\title{
La aportación a la metalexicografía bilingüe española del siglo XIX de Gaspar Melchor de Jovellanos: la Instrucción para la formación de un Diccionario del dialecto asturiano
}

\author{
ÁNGELA GRACIA MENÉNDEZ \\ Universidad de Otago, Nueva Zelanda
}

Este artículo tiene como objeto analizar la Instrucción para la formación de un Diccionario del dialecto asturiano (1801) de Gaspar de Jovellanos desde la perspectiva de su aportación a la metalexicografía bilingüe española del siglo XIX. Dicho escrito (de ahora en adelante Instrucción) es enviada por Jovellanos, como anexo a una carta fechada el 14 de enero de 1801, a su amigo, el clérigo Carlos González de Posada (Jovellanos, 2005a: 286), con el que solía analizar y comentar etimologías. Pese a que la primera versión es redactada hacia 1791, envía una segunda en 1801, por lo que opto por ubicarla a principios del XIX, siendo la de 1801 una segunda redacción o copia (Jovellanos, 2005a: 265, nota 1). Su Instrucción constituye un plan para inventariar el léxico asturiano y explicitar la estructura de la información de cada artículo para un futuro diccionario del asturiano. Por ello puede calificarse de escrito metalexicográfico del siglo XIX, en una fecha en la que los textos de ese tipo solían reducirse a preámbulos de los diccionarios. Tal vez sea su formación como juez la que lo impulsa a reflexionar primero rigurosamente sobre el método y establecerlo explícitamente con el fin de que pueda ser aplicado rigurosamente por todas aquellas personas que participarán en ese proyecto.

El factor externo que condicionó la labor en el Principado de este ilustrado asturiano a partir de 1790 son los cambios políticos ocurridos en Francia tras la Revolución y el temor a un contagio. La orden de Porlier, que lo alejaba de la capital y requería su presencia en Asturias, resultó ser un «destierro disfrazado» según Artola (1999: 44). Sin embargo, esa comisión le permitió llevar «a cabo su mejor obra como político -el Instituto Asturiano-, al tiempo que compondría el más importante de sus tratados doctrinales: el Informe en el expediente de Ley Agraria» (45). En esa época inició su Diario en el que anotaba observaciones artísticas en sus desplazamientos dentro del Principado, pero también todo lo que le parecía relevante con respecto a cuestiones dialectales que atañen al asturiano a finales de siglo.

Para apreciar su valor histórico y cultural es preciso ubicar su proyecto de compilar el léxico asturiano dentro del marco ilustrado de finales del siglo XVIII. Jovellanos es filósofo, economista, jurista, pedagogo, poeta, pero no es filólogo o lexicógrafo en su sentido estricto. Sin embargo, había mostrado su preocupación por cuestiones de len-

ÁNGELA GRACIA MENÉNDEZ, «La aportación a la metalexicografía bilingüe española del siglo XIX de Gaspar Melchor de Jovellanos: la Instrucción para la formación de un diccionario del dialecto asturiano», Revista de Lexicografia, XVII (2011), pp. 83-96. ISSN: 1134-4539, e-ISSN: 2603-667. DOI: https://doi.org/10.17979/rlex.2011.17.0.3784 
gua desde su discurso de recepción ante la Academia Española en 1781 (Gracia Menéndez, 2009). En Las ideas lingüisticas de Gaspar de Jovellanos se abordan varios escritos señalando su aportación a la filología y a la lingüística, ciñéndome para los escritos asturianos más bien a su aportación a la dialectología y ubicándolos en el contexto de los proyectos impulsados por la Academia de la Historia y, en concreto, los Diccionarios regionales (Gracia Menéndez, 2008: 219-256). ${ }^{1}$ Este proyecto del máximo exponente español del Siglo de las Luces se inscribe, por una parte, dentro del afán ilustrado enciclopedista de catalogar todo, pero por otra, se enmarca en un interés por las lenguas regionales, iniciado ya por Fray Martín Sarmiento para el gallego que, según García Arias, lo impulsaría a la codificación del asturiano (1975: 11). El lexicógrafo alemán Franz Josef Hausmann califica los diccionarios como parte de la historia cultural y lingüística de las naciones ${ }^{2} \mathrm{y}$, en ese sentido, ha de concebirse como parte de la historia cultural no solo de Asturias sino de España. La Instrucción ha tenido escasa repercusión fuera de los estudios relacionados con el asturiano. Una razón puede ser que se tratara de un mero plan para un futuro diccionario. Otra razón es que no fuera un proyecto para un diccionario del español sino para un dialecto peninsular, aunque hoy es calificado como lengua (García Arias, 2007: 19). Finalmente, parece decisivo que esta obra no fuera impresa hasta mediados del XIX.

Daniel Droixhe hace mención de las «Instrucciones para la formación del diccionario del dialecto asturiano» que Jovellanos envió a Francisco de Paula Caveda y Sorales en 1791 (1978: 343); el filólogo francés lo califica de «Figure éminente de la dialectologie des Lumières, Jovellanos n'est pas seulement précurseur mais héritier, descendant spirituel explicite de Sarmiento, et en cela, il ilustre parfaitement la continuité que traverse tout le XVIII siècle et l'unit a l'âge suivant» (344). Arias Cabal señala que los primeros trabajos de recopilación de léxico dialectal se publican en el último cuarto del siglo XIX (1996: 41); no menta el diccionario de Posada ni el proyecto del gijonés, cuyas obras se creían perdidas o permanecían inéditas (1996: 42), ${ }^{3}$ aunque menciona a don Gaspar por ser el primer proyecto que se conoce de un diccionario asturiano, pero refiriéndose a la Instrucción de 1791 enviada a Caveda (1996: 43). El lexicógrafo alemán Günter Haensch menciona los escritos jovellanistas sobre el dialecto asturiano, pero no cita su Instrucción (1993a: 1742). Franz Josef Niederehe, al ceñirse a obras de hasta 1800, sólo recoge el Curso de Humanidades Castellanas y sus Rudimentos de gramática castellana (2005: 292, 362 y 345). Hausmann apunta para la metalexicografía española a Casares (1988: 82), pero no menta la «Instrucción» jovellanista. Tampo-

\footnotetext{
${ }^{1}$ En su Discurso sobre el lenguaje y estilo propio de un diccionario geográfico estableció normas de tipo formal para el Diccionario geográfico de Asturias (Jovellanos, 2010). Con la misma finalidad de establecer normas para su presentación redacta su manuscrita Memoria sobre el estilo conveniente de Diccionario Geográfico (Academia de la Historia, legajo 9/5945). Ambas obras reflejan un afán por establecer las normar a seguir antes de proceder con el proyecto en sí aunque no sean planes para un diccionario lingüístico.

${ }_{2}$ «Wörterbücher sind Teil der Kultur- und Sprachgeschichte der Nationen. Ihre Kenntnis sollte zum Bildungskanon gehören» (Hausmann, 1987: 131)

${ }^{3}$ El Diccionario de algunas voces del dialecto asturiano (1788) de Carlos González de Posada fue finalmente publicado dos siglos después, en 1989.
} 
co lo recoge Acero Durántez (2003), posiblemente por considerar el asturiano un dialecto. Ignacio Ahumada señala que «Los escritos metalexicográficos son escasos en el siglo XVIII y aparecen en el siglo XX, exceptuando los prólogos de los diccionarios» (2008: 41); menciona el Apuntamiento sobre el dialecto asturiano (2000: 8, 2007a: 10, 2007b: 27), mas no incluye su Instrucción, que considero de más valor metalexicográfico, y pasa de la reseña del Diccionario de Autoridades por Gregorio Mayans (1731) directamente al Nuevo Diccionario de la lengua castellana por Miguel Antonio Caro (2007a: 14).

En relación a la clasificación establecida por Hausmann (1989) ${ }^{4}$ resulta difícil categorizar la Instrucción en uno de los apartados citados. Al ser un escrito monográfico, cabría incluirla en esta categoría. Por otro lado, Ahumada añade el apartado 1.5 «Los proyectos frustrados» (2007b: 26). En efecto, se trata ciertamente de un proyecto frustrado ya que no pudo llevarlo a término. Una tercera opción sería abrir otra categoría titulada «Plan para un futuro diccionario». En todo caso, considero oportuno añadir la Instrucción jovellanista a la lista de escritos metalexicográficos bilingües del siglo XIX en España, puesto que hasta la fecha no la he encontrado en la relación de escritos españoles de este corte; si supiéramos que es una copia exacta del escrito de 1791 podría incluirse en los escritos metalexicográficos del siglo XVIII. Este artículo pretende analizar y destacar por ello el criterio del ilustrado polígrafo para diseñar este plan desde un punto de vista de su aportación a la metalexicografía española bilingüe del siglo XIX.

Refiriéndose al aprendizaje de lenguas modernas, Manuel Alvar Ezquerra destaca que los diccionarios bilingües tenían una finalidad utilitaria: «normalmente no culturales, sino comerciales, políticas, etc.» (1995: 177). En este aspecto, se distingue este proyecto de los demás por precisamente contribuir a la cultura del Principado. Francisco de Paula Caveda y Solares en su misiva del 4 de julio de 1791 a Jovellanos se explaya en ese sentido: «contribuir [...] a una obra que quizá será el origen de la ilustración del país» (Jovellanos, 1985, 463-464, carta $\mathrm{n}^{\circ} 334$ ). Este comentario nos permite ubicar toda la empresa en un plano más vasto y abstracto: el de ilustrar, por lo que la convierte en un proyecto cultural. En ese sentido, el intelectual gijonés justificó el estudio del asturiano en una carta del 26 de octubre de 1804 en Bellver a González de Posada, con el que contribuiría a formar «la historia de la cultura de nuestro país» en los siguientes términos:

Ni omitiré una reflexión que conviene tenga usted siempre a la vista cuando vaya repasando las palabras de su Diccionario para inferir las ideas que cada una de ellas supone, y por las cuales se puede, por decirlo así, hacer la historia de la cultura de nuestro país (Jovellanos, 1988: 124, carta 1402).

\footnotetext{
${ }^{4}$ Hausmann hace un esbozo histórico de las obras que pueden calificarse como metalexicográficas y distingue cuatro fuentes: 1. aquéllos escritos que son prefacios, 2. críticas a diccionarios, 3. artículos metalexicográficos en los diccionarios, 4. escritos monográficos (1989: 216-217).
} 
A pesar de ser Jovellanos miembro de la Academia de la Historia desde 1780 y de la Española desde 1781, este escrito ha de calificarse de no académico por ser monográfico y no haber sido elaborado por un conjunto de académicos, aunque la empresa fuera perfilada para una futura Academia asturiana desde un principio. Al ser miembro de la Real Academia Española es muy probable que estuviera familiarizado con el planteamiento metodológico para la confección del diccionario castellano, a través de lo que Álvarez de Miranda califica de «primeros textos metalexicográficos [...] que tenemos en nuestra lengua» que elaboró la Academia Española a lo largo del siglo XVIII: «sencillos manuales de uso interno que sirvieran de guía a sus individuos», o sea, pequeñas cartillas, la Planta para Autoridades impresa en 1713 y las Nuevas reglas que ha formado la Academia Española para la corrección y aumento del Diccionario de 1757 (2000: 42-43).

Consciente de la importancia de tener el apoyo real para dicha empresa, García Arias señala que tenía por ello previsto fundar también una Academia Asturiana de Buenas Letras en analogía a la Academia Española (2007: 9). Esa idea fue compartida por Caveda y ya expresada en 1791. Por ello, discierne don Gaspar en su plan desde un principio entre la labor de los colectores para la recolección del léxico y la de los formantes; ciertas labores, como la que afecta a la ortografía o la corrección, las reserva Jovellanos al cuidado de la futura Academia en una reunión plenaria (2005a: 267). En analogía al Diccionario de Autoridades, procura aportar usos concretos que se han dado en la literatura si bien las reduce a 3 :

Finalmente, apuntará cualquier autoridad que hallare para prueba del uso y acepción o significación de cada palabra.

Estas autoridades no se pueden tomar sino de tres orígenes:

$1^{\circ}$, de refranes asturianos;

$2^{\circ}$, de cantares usados en las danzas, endechas, esfoyazas, y otras juntas y diversiones del pueblo de Asturias.

$3^{\circ}$, de poesías correctas y genuinas de autores antiguos, conocidos y acreditados, escritas en idioma de nuestro dialecto, llamado comúnmente $B a$ ble, como por ejemplo, las de Antonio González, conocido por el nombre de Antón de Mari-Reguera; las de Juan Fernández Porley, llamado Juan de la Candonga; las de don Bernardino de Robledo, cura de Piedeloro; el romance Pintura caballo de Benavides, etc. (Jovellanos, 2005a: 269-270).

\section{Planteamiento metalexicográfico de Jovellanos}

El valor metalexicográfico de su Instrucción se caracteriza por:

Explicitar los principios por los que se rige su autor para confeccionar un futuro diccionario que deben seguir los colaboradores de este proyecto.

Incluir información relativa a la etimología y la ortografía. Incluir aspectos sintácticos en su planteamiento. 
Tener como referencia las autoridades en asturiano pero también el uso de sus hablantes.

Aspirar a fijar el significado y la pronunciación y servir así como norma para sus hablantes.

La Instrucción constituye un plan para la compilación de un diccionario bilingüe y diferencial del asturiano, comúnmente denominado bable, ya que pretende compilar estrictamente el vocabulario asturiano, excluyendo el que es idéntico al léxico castellano y, en consecuencia, aquel que aparece en el Diccionario de la Real Academia Española (266). Al tratarse de variedades románicas hay palabras que son usadas en ambas, como bien señala García Arias, que califica su criterio de «excesivamente restrictivo» (Jovellanos, 2005a: 265, nota 3). La lengua de partida es el castellano, mientras que la lengua meta es el asturiano, por lo que se trata de un proyecto para un diccionario bilingüe. En la última edición de sus Obras Completas de 2005 se incluyen en el tomo titulado Escritos asturianos algunas cédulas (2005c: 287-291) que había preparado para dicho diccionario. Sin embargo, éstas no reflejan la complejidad que Jovellanos explicita en su plan y, por ello, no las considero representativas.

Explicita que «deberá contener todas la palabras que pertenecen peculiar y exclusivamente al dialecto que se habla en los pueblos de Asturias» (265). Sin embargo, añade que

También pertenecen al presente diccionario las frases familiares y proverbiales, y los modos adverbiales del mismo dialecto.

Finalmente, pertenecerán a él los refranes o adagios peculiares suyos, aunque no los tomados de la lengua castellana. (2005a: 266)

Jovellanos establece que el proyecto consta de dos partes esenciales, la primera es la recopilación del corpus asturiano y corresponde a los colectores y los formantes llevarán a cabo lo que respecta a la redacción del artículo lexicográfico:

Su composición constará de dos partes principales, a saber: la colección de las palabras y la formación de las cédulas, y para una y otra se nombrarán académicos que viven fuera de la capital, porque residiendo en los mismos concejos, y en diferentes parroquias y territorios, podrán recoger más fácilmente las palabras que están en uso por todo el Principado (2005a: 266).

\section{LA RECOPILACIÓN DEL LÉXICO ASTURIANO}

Observador y, en consecuencia, conocedor de la situación lingüística en el Principado, que podría calificarse de diglosia, y con el fin de que la recolección fuera más precisa y exacta, expresa el deseo de que el diccionario se realizara en el Principado y no en Madrid. Arguye en una carta del 30 de agosto de 1800 a Juan de Llano Ponte que como se trata del asturiano, correspondería su estudio y análisis también a una institución ubicada en el Principado y no en la capital: «¿No es una vergüenza que una Aca- 
demia que está a dos leguas de nosotros, trabaje un diccionario de Asturias con materiales enviados de Asturias, y que nosotros lo suframos con nuestras manos cruzadas? Así que la cosa a mi juicio no es de despreciar» (1986: 564, carta 1296). Cabe inferir que se refiere a la Academia de la Historia, cuyo segundo director Pedro Rodríguez de Campomanes había impulsado varios Diccionarios histórico-geográficos de España en el marco científico ilustrado en el cual se inscriben. En todo caso, Jovellanos se propone llevar a cabo un diccionario lingüístico, en oposición a los geográficos tan extendidos en el siglo XVIII y en el que él también llevaba trabajando para el tomo de Asturias.

Su capacidad de observación y su sensibilidad por las tendencias lingüísticas en regiones alejadas de Oviedo se hace palpable puesto que en su «Carta interrumpida sobre el dialecto asturiano» llega a la conclusión de que el asturiano - se supone que en Oviedo, la sede administrativa —, estaba corrompido por la lengua estándar:

En efecto para hacerlas con fruto era necesario huir de las poblaciones agregadas, donde la residencia de la nobleza, alto clero y gente de letras, la concurrencia de forasteros y el uso más frecuente de la lengua castellana, han corrompido el dialecto popular, desterrando de él muchas voces, admitiendo muchas puramente castellanas y alterando su pronunciación y aún su sintaxis. Era también preciso buscar los concejos más interiores y de menos trato y comercio con los pueblos agregados, residir en ellos despacio, oír, preguntar, escribir, comparar y, en fin, hacer un estudio detenido y reflexivo de mi objeto (2005e: 156-157).

Trasciende este escrito una mera obra lexicográfica al tener primero por objeto el establecimiento del corpus, puesto que Jovellanos no puede remitirse a un diccionario asturiano previamente establecido. Las fuentes primarias para ese diccionario ahora son orales. En su manuscrito autógrafo «Sobre el Vocabulario del dialecto y el Diccionario geográfico de Asturias» (2005d) se explaya con respecto al método de recopilación. Se desprende que procura aplicar el método de las ciencias naturales, en concreto, opta por el método de encuestas como hiciera Sarmiento y Tomás López para el Diccionario geográfico (1985: 22-23). A juzgar por la siguiente cita, no hallamos una disociación entre un método para las ciencias naturales y otro para la recopilación del léxico, área de investigación que pertenece a las humanidades. Esa analogía a la recopilación de una planta o mineral que caracteriza el empirismo del siglo XVIII le obliga a hacer una recopilación basándose en la observación de hechos, en este caso, de palabras enunciadas:

No están encerradas en las bibliotecas ni archivos, sino en el gran libro de la naturaleza, ni hay necesidad de leerlas ni estudiarlas, sino que, presentándose a todas horas a nuestro oído y nuestra vista, se trata solo de recogerlas, apuntarlas y traerlas al depósito de nuestra academia (2005d: 260).

Pese al valor que Jovellanos atribuyera como académico y jurisconsulto a documentos escritos, sean legales o literarios, es consciente de que el asturiano carecía de una tradición literaria comparable al castellano por lo que aceptó basarse en el uso y permitió el criterio que tuviera el académico competente: «Cuando no se hallare autoridad en 
que apoyar el uso, como sucederá con frecuencia, entonces se pondrá una frase o ejemplar en que se emplee la misma palabra según su verdadera aceptación» (2005a: 271) Destaca el hecho de que permitiera recurso al uso coetáneo de la palabra en cuestión. No excluyo cierta influencia del Diccionario de Terreros y Pando que se basa en el uso para incluir las voces en su obra. En este sentido, don Gaspar equipara el 'uso establecido' a la 'tradición escrita' que tiene el asturiano. García Arias observa también un propósito normativo pues ha de servir como codificación del asturiano (1975: 11). Esa motivación explicaría el hecho de que pretendiera dar un ejemplo de los verbos en el tiempo menos utilizado razonando que es con el fin de difundir el asturiano correcto. Contiene pues un elemento prescriptivo y además pedagógico. El futuro diccionario ha de servir como punto de referencia para los hablantes del Principado. Coexisten así el carácter descriptivo y el prescriptivo.

En un segundo repartimiento por materias se propone dar una organización onomasiológica. Este tipo de organización onomasiológica no es nueva, pues Sarmiento ya expresó su intención de optar por dicha ordenación para el léxico gallego. ${ }^{5}$ Añade: «Para que el repartimiento por materias sea menos embarazoso, se dividirán todas las palabras en cuatro clases: $1^{\mathrm{a}}$, las pertenecientes a la historia natural; $2^{\mathrm{a}}$, las pertenecientes a industria; $3^{\mathrm{a}}$, las de uso doméstico; $4^{\mathrm{a}}$, las de uso común o indiferente.» (268)

Establece que es también labor de los colectores fijar sus correspondencias al castellano, lo que es dar una traducción: «Será a cargo del colector poner al lado de cada palabra la equivalente castellana si la hubiere, y si no, explicar breve y claramente la significación de cada una» (269). Ello convierte su «Instrucción» en un plan para un diccionario bilingüe.

\section{LA MiCROESTRUCTURA DE LAS CÉDULAS}

La segunda parte de su plan describe la labor de los formantes, un grupo que «se compondrá de cuatro o seis individuos residentes en la capital, que nombrará la Academia» y cuya función es «el arreglo y la formación de todas las cédulas del diccionario» (272). Para ellas prevé una ordenación alfabética de las entradas. Ello hubiese convertido su futuro diccionario en una organización semasiológica que además inclúa «frases familiares y proverbiales, y los modos adverbiales del mismo dialecto» (266), lo que implica un eje adicional, el sintagmático. Titula un tercer apartado «De la corrección de las cédulas» (281). Se propone inventariar el léxico asturiano (265-271), incluir información sobre autoridades (270), definición del significado (273), correspondencia castellana y latina (274), etimología (274), pronunciación y ortografía (275).

${ }^{5}$ Günther Haensch señala que también se había llevado a cabo en el Promptuario trilingüe de Broch (1771) (1993b: 1772). 
Establece que las correspondencias, las etimologías, las autoridades y las frases ejemplares sean a cargo de los formantes (271).

\subsection{El significado y la correspondencia}

Se fijará primero la pertenencia de la palabra al léxico asturiano y después su significación (273). Se desprende de la siguiente cita de que es consciente de cuán difícil es definir adecuadamente el significado y de su relevancia para el diccionario:

$1^{\text {a }}$ Que esta es la parte más difícil e importante de su encargo, pues nada puede sobrar ni faltar en las definiciones de las palabras, que no tenga una influencia inmediata en la perfección del diccionario.

$2^{\mathrm{a}}$ Que para hacer una buena definición se necesita gran conocimiento y gran tino, puesto que toda sabiduría consiste en conocer muchas cosas, tener acerca de ellas ideas claras y distintas, y saberlas comunicar a otros por medio de palabras.

$3^{\text {a }}$ Que la definición debe contener una idea breve, clara y distinta del carácter, significación y uso de cada palabra (273).

Contiene al mismo tiempo un elemente normativo, como ya se ha dicho, al «fijar la verdadera significación de cada palabra» (273). Dar la correspondencia latina es labor de los formantes: «De la definición de cada palabra se pasará a fijar la correspondencia latina» (274).

\subsection{La etimología, la pronunciación y la ortografía}

Tras haber fijado las correspondencias «se procederá a averiguar las etimologías». Esta cuestión resulta delicada ya que el establecer la etimología puede ayudar a determinar la correspondencia. Puntualiza:

En la averiguación de las etimologías se procederá con el mayor cuidado por los formantes; pues aunque se suponga de ordinario que este trabajo es de poca importancia, la experiencia acreditará muy luego de cuánta utilidad sea para la perfección de la empresa.

Acaso no está en descrédito semejante estudio, sino por la arbitrariedad con que se han dado a él personas ignorantes de los orígenes de las lenguas, sin cuyo íntimo conocimiento es fácil caer en absurdos y desvaríos (274).

Refleja una actitud crítica con respecto a la etimología, que había expresado en varias ocasiones, ya que no era aún una disciplina científica. Pese a que remite a los formantes a la lectura de Gregorio Mayans, Martín Sarmiento, Sebastián de Covarrubias y Bernaldo Alderete (274) advierte de las «notables equivocaciones» de estos dos últimos estudiosos. Al incluir la etimología de cada palabra incorpora el eje diacrónico.

Después propone fijar la pronunciación y la ortografía:

Una vez determinada la raíz de cada palabra, se determinará para ella su verdadera pronunciación, y se tratará de escribirla con arreglo a ésta. Por el mismo medio se fijará la escritura de cada palabra, resultando de un 
mismo principio general la verdadera prosodia y la ortografía de nuestro dialecto (275).

Con respecto a la ortografía establece que «Por lo mismo, así los colectores de las cédulas por orden alfabético se detendrán poco en la averiguación de la ortografía con que debe escribirse cada una, reservando este cuidado a la Academia» (267). Al no basarse en un corpus escrito se topa con problemas que atañen a la ortografía. Propone establecer la escritura basándose en la pronunciación. Cabe inferir que es la raíz de cada palabra, o sea, la etimología, la que servirá para establecer la pronunciación y, en consecuencia, la ortografía. Su preocupación por establecer la ortografía revela su afán por una codificación del asturiano, en analogía a como se venía haciendo a lo largo del siglo XVIII para la lengua española. Obviamente no podían equipararse ambas lenguas en aquellas fechas: el asturiano, considerado históricamente dialecto asturleonés, fue utilizado durante la Edad Media para documentos escritos, pero debido al avance del castellano se vio paulatinamente postergado a un lenguaje hablado. Jovellanos se halla en una difícil situación en la que el número de documentos redactados en asturiano son escasos y no le sirven para establecer un corpus de referencia. Es posible que fuera esa carencia de documentos escritos la que le obligara a replantearse el método para formar el diccionario. Sigue el planteamiento de la Academia Española para el Diccionario de Autoridades y no el del $D R A E$ de 1780 que suprime las etimologías.

En principio, se propone partir de la etimología salvo si carece de orígenes latinos:

Cuando no se hallase la raíz de la palabra asturiana en la buena latinidad, se buscará en la latinidad media e ínfima, donde se encontraran muchas raíces.

A falta de estos orígenes, se ocurrirá a las lenguas del norte, donde se hallará el de muchas palabras, como por ejemplo, pote y calamieres, que vienen de pot y gremillers, que tienen la misma significación en las lenguas inglesa y francesa (275).

Sin embargo, el recurso al uso que tuvieran los formantes incluye también la sincronía. Coexisten pues la perspectiva diacrónica, por incorporar las etimologías, y la sincrónica al aceptar también el uso de los hablantes en aquellas fechas. Recordemos su interés por aplicar un método empírico que influyó ciertamente en fijarse en el uso.

\subsection{El elemento sintáctico}

Estipula dar una frase completa para cada lema, con el fin de ejemplificar su uso. Su profundo conocimiento como gramático además lo guía para darle la importancia que merece a la morfología de los verbos por sus irregularidades en la formación de los tiempos, por lo que recurre a dar como ejemplo una frase «en aquel tiempo de su conjugación en que más se distinga de la castellana, para que así se difunda mejor el conocimiento de nuestro dialecto» (346). Esa observación señala que no es un mero inventario del léxico asturiano, sino que procura a la vez fijar el uso y que sirva de referencia para los hablantes de esa región. Pero como el conocimiento morfológico de un verbo no es suficiente para garantizar que un hablante sepa utilizarlo de manera correcta en 
una frase completa, Jovellanos incluye además información sintáctica en la microestructura con respecto a los complementos que rige el verbo en cuestión: «Con el mismo fin, y para dar una idea más exacta de los verbos, se indicará su verdadero régimen, haciendo que la frase sea un exacto ejemplo del que pertenece a cada uno» (346).

En efecto, se puede medir la calidad de un diccionario por la información sintáctica que incluye. Cuánta más información abarque cada entrada con respecto a los complementos y preposiciones que rige el verbo, mejor será el diccionario, puesto que facilita al usuario la totalidad de información que lo capacita para formar una frase correcta. Esa información sintáctica previa además resultaría esencial como base para redactar una gramática del asturiano que para Jovellanos era el siguiente proyecto. Demuestra una capacidad extraordinaria a la hora de identificar lo que es una información fundamental desde un punto de vista lexicográfico para que un hablante pueda formar frases correctas. El hecho de que le atribuyera esa importancia a la sintaxis lo hubiese convertido en un diccionario complejo por incluir el eje sintagmático.

En conclusión, la «Instrucción» se inserta en la tradición lexicográfica peninsular del siglo XVIII, pero su planteamiento metalexicográfico explícito previo a una recopilación anticipa enfoques del XIX. Jovellanos procede para este plan con el rigor, la capacidad de reflexión y presupuestos metodológicos que lo caracteriza como individuo ilustrado. Establece el marco teórico abstracto para acercarse al estudio empírico de cualquier habla. Puesto que no existían parámetros para la recopilación empírica del léxico, Jovellanos aplica la metodología empírica de otras disciplinas al estudio del habla, es decir, a la de las realizaciones concretas. En una época que Ángel del Río califica de «pre-científica» (214), Jovellanos logra formular pautas rigurosas para una recopilación del léxico que sirviera después para elaborar una gramática del asturiano. Con esa Instrucción demuestra su capacidad de reflexionar sobre diversos aspectos relacionados con el estudio científico de la lengua, como la formación del corpus, la etimología, la relación entre pronunciación y ortografía y la sintaxis, teniendo como punto de referencia algunas autoridades en asturiano pero incluyendo también el uso del asturiano por sus hablantes coetáneos, lo que lo convertiría en un proyecto complejo y ambicioso de haberse llevado a cabo. Hay que tener presente que las subdisciplinas filológicas no se habían establecido aun como disciplinas científicas en esa época. Jovellanos da un primer paso para establecer el método para su estudio siempre partiendo de principios científicos como en este caso el empirismo con el fin de llegar a conclusiones válidas por su rigor, capacidad de análisis y crítica, puesto que si las bases para su recopilación son deficientes, lo será también el inventario que se obtiene. Su proyecto lexicográfico no es meramente enciclopédico sino que tiene una finalidad ilustrada bastante más amplia: la de contribuir a la cultura del Principado. Por la fecha en la que fue redactada, su declaración de principios previa a cualquier labor y la complejidad conceptual para la formación de un diccionario bilingüe, resulta ser un escrito de los más antiguos de la metalexicografía española y uno de los más explícitos por razonar su procedimiento como guía para todos los colaboradores del futuro proyecto. Desafortunadamente, el máximo exponente de la Ilustración española fue llevado y confinado a Bellver durante siete años solo pocos días después de enviar este escrito a Posada, lo que le impidió llevar el proyecto a buen término. Cuando se conmemora el 
segundo centenario de su muerte en 1811, su planteamiento mantiene validez y nos permite apreciar su aportación a la historiografía lingüística española, en concreto, a la metalexicografía española bilingüe del siglo XIX.

\section{REFERENCIAS BIBLIOGRÁFICAS}

ACERO DURÁNTEZ, Isabel (2003): «La lexicografía plurilingüe del español», en Antonia M. Medina Guerra, coord., Lexicografía española, Barcelona, Ariel.

AHUMADA LARA, Ignacio (2000): «Lexicografía y metalexicografía», en Diccionario bibliográfico de la metalexicografia del español. (Siglos XVIII-XIX), Jaén, Universidad de Jaén, pp. 1-17.

(2004): «Exigencias al diccionario monolingüe de aprendizaje», en S. Ruhstaller y L. Berguillos, eds., La competencia lingüistica y comunicativa en el aprendizaje del español como lengua extranjera, Madrid, Edinumen, pp. 83-96.

(2007a): «Bibliografía de la metalexicografía del español: la crítica de diccionarios (ss. XIV al XIX)», en Mar Campos Souto, Rosalía Cotelo García y José Ignacio Pérez Pascual, eds., Historia de la lexicografia española, Anexos de Revista de Lexicografia, 7, A Coruña, Universidad de A Coruña, pp. 9-19.

(2007b): «La metalexicografía del español: revisión y perspectivas», en Félix San Vicente, ed., Perfiles para la historia y crítica de la lexicografia bilingüe del español, Monza, Polimetrica Internacional Scientific Publisher, pp. 15-33.

(2008): «De los primeros tratados metalexicográficos del español (Siglos XVIII y XIX)», en Dolores Azorín Fernández y otros, eds., El Diccionario como puente entre las lenguas y las culturas del mundo, Alicante, Universidad de Alicante-Biblioteca Virtual Cervantes, pp. 41-45 [http://descargas.cervantesvirtual.com/servlet/SirveObras/123 61639010179384210213/031299.pdf?incr=1].

AlVAR EZQUerRA, Manuel (1995): «Los diccionarios del español en su historia», International Journal of Lexicography, 8, 3, pp. 173-201.

(2007): «Panorama de la lexicografía del español en el siglo XVIII», en Josefa Dorta, Cristóbal Corrales y Dolores Corbella, eds., Historiografia de la lingüistica en 
el ámbito hispánico. Fundamentos epistemológicos y metodológicos, Madrid, Arco/Libros, pp. 269-314.

Álvarez de MirandA, Pedro (2000): «La lexicografía académica de los siglos XVIII y XIX», en Ignacio Ahumada, ed., Cinco siglos de lexicografia del español. IV Seminario de Lexicografía Hispánica. Jaén, 17 al 19 de noviembre de 1999, Jaén, Universidad de Jaén, pp. 35-62.

(2007): «Panorama de la lexicografía española en el siglo XIX», en Josefa Dorta, Cristóbal Corrales y Dolores Corbella, eds., Historiografía de la lingüística en el ámbito hispánico. Fundamentos epistemológicos y metodológicos, Madrid, Arco/Libros, pp. 329-356.

ARIAS CABAL, Álvaro (1996): «La lexicografía asturiana. Cronoloxía de doscientos años d'intentos», Lletres Asturianes, 60, pp. 41-63.

BARRIO EsTÉVEZ, Laura del y Sergio TORNER CASTELls (1994-1995): «Información diacrónica en el Diccionario de la Lengua Española de la Real Academia Española (Vigésima Primera Edición)», Revista de lexicografía, I, pp. 29-54.

DroIXHE, Daniel (1978): La Linguistique et l'appel de l'histoire (1600-1800). Rationalisme et révolutions positivistes, Genève, Librairie Droz.

ESPARZA TORRES, Miguel Ángel (2007): «Los inicios de la Lexicografía en España», en Josefa Dorta, Cristóbal Corrales y Dolores Corbella, eds., Historiografía de la lingüística en el ámbito hispánico. Fundamentos epistemológicos y metodológicos, Madrid, Arco/Libros, pp. 231-258.

GARCÍA ArIAS, Xosé Lluis (1975): Bable y Regionalismo, Oviedo, Gofer.

(2007): «De la dialeutoloxía a la llingua nel dominio llingüísticu ástur», Lletres Asturianes, 94, pp. 7-26.

GonZÁLEZ DE PosADA, Carlos (1989): Diccionario de algunas voces del dialecto asturiano (1788) y otros papeles, Oviedo, Biblioteca de Filología Asturiana.

Gracia MenÉndez, Ángela (2008): Las ideas lingüisticas de Gaspar de Jovellanos, Gijón, Fundación Foro Jovellanos.

(2009): «Una primera aproximación hermenéutica de Gaspar de Jovellanos», en José María García Martín, dir., y Victoriano Gaviño Rodríguez, ed., Las ideas y realidades lingüísticas en los siglos XVIII y XIX, Cádiz, Universidad de Cádiz, pp. 329-343.

HAENSCH, Günther (1993a): «Lexikographie der Einzelsprachen II. Die romanischen Sprachen», en F. J. Hausmann, O. Reichmann, H. E. Wiegand y L. Zgusta, eds., 
Wörterbücher. Ein internationales Handbuch zur Lexikographie, Berlin, Walter de Gruyter, pp. 1738-1767.

(1993b): «Katalanische Lexikographie», en F. J. Hausmann, O. Reichmann, H. E. Wiegand y L. Zgusta, eds., Wörterbücher. Ein internationales Handbuch zur Lexikographie, Berlin, Walter de Gruyter, pp. 1770-1788.

HAUSMANN, Franz Josef (1986): «La métalexicographie à l'échelle mondiale», en Ramón Lorenzo, ed., Coloquio de Lexicografía, Santiago de Compostela, Universidad de Santiago, pp. 79-109.

(1987) «Sprachwissenschaft im Wörterbuchvorwort. Das französisch-lateinische Wörterbuch des Pierre Danet (1673-1691», en Hans-Josef Niederehe y Brigitte Schlieben-Lange, eds., Die Frühgeschichte der romanischen Philologie, von Dante bis Diez, Beiträge zum deutschen Romanistentag in Siegen, 30.9.- 3.10. 1985, Tübingen, Narr, pp. 123-133.

(1989): «Pour une histoire de la métalexicographie», en Handbuch zur Sprachund Kommunikationswissenschaft, Berlin, de Gruyter, 5, pp. 216-224.

Jovellanos, Gaspar de (1956): Obras publicadas e inéditas de Gaspar Melchor de Jovellanos, ed. de Miguel Artola, tomo I, Madrid, Atlas.

(1985): Obras completas, tomo II, Correspondencia 1, ed. de José Miguel Caso González, Oviedo, Instituto Feijoo.

(1986): Obras completas, tomo III, Correspondencia 2, ed. de José Miguel Caso González, Oviedo, Instituto Feijoo.

(1988): Obras completas, tomo IV, Correspondencia 3, ed. de José Miguel Caso González, Oviedo, Instituto Feijoo.

(2005a): «Instrucción para la formación de un Diccionario del dialecto asturiano (1801)», en Obras completas, tomo IX, Escritos Asturianos, ed. de Elena de Lorenzo y Álvaro Ruiz de la Peña, Oviedo, Instituto Feijoo, pp. 263-286.

(2005b): «Apuntamiento sobre el dialecto asturiano (1804)», en Obras completas, tomo IX, Escritos Asturianos, ed. de Elena de Lorenzo y Álvaro Ruiz de la Peña, Oviedo, Instituto Feijoo, pp. 295- 322.

(2005c): «Cédulas para el Diccionario (1801)», en Obras completas, tomo IX, Escritos Asturianos, ed. de Elena de Lorenzo y Álvaro Ruiz de la Peña, Oviedo, Instituto Feijoo, pp. 287-291. 
(2005d): «Sobre el Vocabulario del dialecto y el Diccionario geográfico de Asturias», en Obras completas, tomo IX, Escritos Asturianos, ed. de Elena de Lorenzo y Álvaro Ruiz de la Peña, Oviedo, Instituto Feijoo, pp. 259-262.

(2005e): «Carta interrumpida sobre el dialecto asturiano», en Obras completas, tomo IX, Escritos Asturianos, ed. de Elena de Lorenzo y Álvaro Ruiz de la Peña, Oviedo, Instituto Feijoo, pp. 155-159.

(2010): «Discurso sobre el lenguaje y estilo propio de un diccionario geográfico», en Obras completas, tomo XIV, Escritos pedagógicos 2, ed. de Olegario Negrín Fajardo, Oviedo, Ayuntamiento de Gijón, Instituto Feijoo, pp. 1294-1299.

«Memoria sobre el estilo conveniente de Diccionario Geográfico», manuscrito, Madrid, Real Academia de la Historia, legajo 9/5945.

LÓPEZ, Tomás (1985): Diccionario geográfico de Tomás López, Almería, edición y estudio de Cristina Segura, Granada, Anel.

Medina Guerra, Antonia M., coord. (2003): Lexicografía española, Barcelona, Ariel.

NIEDEREHE, Hans Josef (2005): Bibliografía cronológica de la lingüística, la gramática y la lexicografía del español (1701-1800), Amsterdam, John Benjamins.

REAl ACAdEMia Española (1984 [1771]): Gramática de la Lengua Castellana, edición facsímile con introducción de Ramón Sarmiento, Madrid, Editora Nacional.

Río, Ángel del (1943): «Los estudios de Jovellanos sobre el dialecto de Asturias», Revista de Filología Hispánica, 3, pp. 209-243. 